\title{
A SHORT EXTENSION OF TWO OF SPIRA'S RESULTS
}

\author{
T. S. TRUDGIAN
}

Abstract. Two inequalities concerning the symmetry of the zeta-function and the Ramanujan $\tau$-function are improved through the use of some elementary considerations.

Mathematics subject classification (2010): 11M26.

Keywords and phrases: Riemann zeta function, Ramanujan tau function, Riemann hypothesis.

\section{REFERENCES}

[1] B. C. BERndT, On the zeros of a class of Dirichlet series, I, Illinois J. Math., 14:244-258, 1970.

[2] R. D. DixON AND L. SCHOENFELD, The size of the Riemann zeta-function at places symmetric with respect to the point $\frac{1}{2}$, Duke Math. J., 33:291-292, 1966.

[3] S. NAZARDonyavi And S. YakUbovich, Another proof of Spira's inequality and its application to the Riemann hypothesis, J. Math. Inequal., 7:167-174, 2013.

[4] F. SAIDAK AND P. ZvENGROWS KI, On the modulus of the Riemann zeta function in the critical strip, Math. Slovaca, 53 (2):145-172, 2003.

[5] R. SPIRA, An inequality for the Riemann zeta function, Duke Math. J., 32:247-250, 1965.

[6] R. SPIRA, Calculation of the Ramanujan $\tau$-Dirichlet series, Math. Comp., 27 (122):379-385, 1973.

[7] E. C. Titchmarsh, The Theory of the Riemann zeta-function, Oxford Science Publications. Oxford University Press, Oxford, 2nd edition, 1986. 